This item was submitted to Loughborough's Research Repository by the author.

Items in Figshare are protected by copyright, with all rights reserved, unless otherwise indicated.

\title{
A review of community electrical energy systems
}

PLEASE CITE THE PUBLISHED VERSION

http://dx.doi.org/10.1109/ICRERA.2016.7884528

PUBLISHER

(c) IEEE

VERSION

AM (Accepted Manuscript)

LICENCE

CC BY-NC-ND 4.0

REPOSITORY RECORD

Strickland, Dani, Mina Abedi Varnosfaderani, J. Scott, P. Quintela, A. Duran, R. Bravery, A. Corliss, K. Ashworth, and S. Blois-Brooke. 2019. "A Review of Community Electrical Energy Systems". figshare. https://hdl.handle.net/2134/24986. 


\section{A Review of Community Electrical Energy Systems}

\author{
D Strickland, M Abedi Varnosfederani, J Scott \\ Energy and Applied Science \\ Aston University \\ Birmingham, UK \\ d.strickland@aston.ac.uk
}

\author{
A Duran, \\ EA Technology \\ Capenhurst Technology Park \\ CapenhurstUK
}

\author{
P Quintela, \\ e2E \\ Welwyn Garden City,UK \\ R Bravery, \\ City of Wolverhampton Council \\ Woverhampton, UK
A Corliss, K Ashworth, S Blois-Brooke Encraft \\ Leamington Spa, UK
}

\begin{abstract}
This paper is aimed at new entrants into the field of electrical community energy. It reviews some of the work that is underway into community electrical energy projects. This review includes a summary of key issues and components which need consideration including some or all of the following; demand side management, energy storage (including vehicle to grid) and renewable generation. The paper looks further into the energy management schemes of these projects and summarises previously published methodology in the area.
\end{abstract}

Keywords-community energy; energy storage; renewable generation; energy management; Virtual power plant; Virtual Energy District

\section{INTRODUCTION}

Community Energy schemes have tended to focus on provision of thermal energy to increase community efficiency through the sharing of heat generating plant and the associated costs. Heat from biomass and combined heat and power schemes have made effective candidates for community scale district heating systems [1] with the business model depending on the communities' longevity of demand to secure finance. Recently more advanced community energy systems have attracted industrial and academic interest as the number and variety of deployments has increased [2] and as the role of decentralized and community energy has gained recognition as a method for decarbonizing energy systems [3]. It is thought that properly integrated local energy systems can provide additional benefits to the wider energy system. [4]. The reasons behind undertaking a community energy scheme may include increased energy supplier profit, reduced customer bills, more independence from the grid and reduced emissions (in terms of both carbon and air quality).

Schemes where electrical energy is dealt with at a community level are under consideration for several reasons; they offer the opportunity for communities to reduce their energy bills and there is opportunity to support stakeholders in the wider electrical system such as Distribution Network Operators (DNO's) or Transmission Network Operators (TNO's) by reducing peak load to help with Network constraints or assist with demand upturn or down turn to contribute to Network stability for example. These community schemes offer the opportunity to adjust Community Network demand/generation through the use of renewable energy resources such as small wind turbines or PV panels, demand side management and energy storage including Vehicle to Grid schemes. Although at a high level such schemes sound straightforward, in practice there are a number of issues to be resolved. These include technical issues such as; the scheme layout and adaptability and scalability, sizing issues, the control strategy, and the energy management strategy. While from a financial aspect, there are questions around profitability and pay back periods along with metering consideration and regulatory issues. There are thousands of published papers into "community energy" in the last five years. This paper looks at a summary of the main points arising from this literature to act as a guide to new entrants in the field and provide references from which additional information can be gathered.

\section{COMMUNITY ENERGY LAYOUT SCHEMES}

To help define and sort the different published community energy schemes into type there are a number of definitions that are needed as shown in Table I. This paper concentrates on community energy where the community is defined as domestic properties which may include small industrial/commercial users as opposed to large industrial parks or large "lumped" energy schemes. One of the advantages of a community network is making sure that the community is considered as a unit so that it has greater negotiation power over energy contracts. Consequently metering arrangements also need to be considered. A number of different community based layouts that could be used are shown in Fig. 1. These include; a small isolated grid such as an island community, with some or all of the community energy managed, and a small area of Network, such as downstream of an $11 \mathrm{kV}$ transformer. This offers a good structure for helping with local DNO constraints. The third

Sponsored by Innovate UK and EPSRC project ORCSEN 
scheme is a fully distributed scheme over a larger area of the Network possibly though a Virtual Power Plant (VPP) styled interface which can have DNO and TNO related benefits.

TABLE I.

TERMINOLOGY

\begin{tabular}{|c|c|c|}
\hline & Terminology & Definition \\
\hline VPP & $\begin{array}{l}\text { Virtual Power } \\
\text { Plant }\end{array}$ & $\begin{array}{l}\text { A cluster of dispersed generator units, } \\
\text { controllable loads and storages systems, } \\
\text { aggregated in order to operate as a unique } \\
\text { power plant. [5] }\end{array}$ \\
\hline VED & $\begin{array}{ll}\text { Virtual } & \text { Energy } \\
\text { District } & \end{array}$ & $\begin{array}{l}\text { A localised area where different residential } \\
\text { and/or industrial users coexist, requiring } \\
\text { or producing energy. [6] }\end{array}$ \\
\hline HEM & $\begin{array}{l}\text { Home Energy } \\
\text { Management } \\
\text { Systems }\end{array}$ & $\begin{array}{l}\text { System to control energy management in } \\
\text { domestic properties. }\end{array}$ \\
\hline DSM & $\begin{array}{l}\text { Demand Side } \\
\text { Management }\end{array}$ & $\begin{array}{l}\text { The change in customer energy demand in } \\
\text { response to a controlling factor. }\end{array}$ \\
\hline $\begin{array}{l}\text { DSR/ } \\
\text { DR }\end{array}$ & $\begin{array}{l}\text { Demand Side } \\
\text { response/demand } \\
\text { response }\end{array}$ & $\begin{array}{l}\text { A form of DSM where customer load is shifted } \\
\text { from key times by means of a financial } \\
\text { incentive. }\end{array}$ \\
\hline $\begin{array}{l}\text { EV/ } \\
\text { HEV/ } \\
\text { PHEV }\end{array}$ & $\begin{array}{l}\text { Electric vehicle/ } \\
\text { Hybrid Vehicle/ } \\
\text { Plug in Hybrid } \\
\text { Vehicle }\end{array}$ & $\begin{array}{l}\text { In the context of community energy it is } \\
\text { assumed that these are all connectable to the } \\
\text { grid and act as an electrical load. }\end{array}$ \\
\hline V2G & Vehicle to grid & $\begin{array}{l}\text { An EV/HEV or PHEV which may act as a } \\
\text { source of energy to the community as well as a } \\
\text { load. }\end{array}$ \\
\hline
\end{tabular}

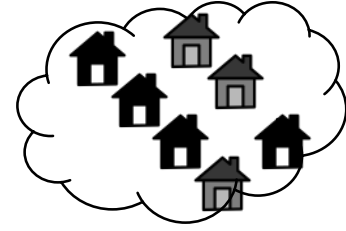

Miro-grid e.g. small island

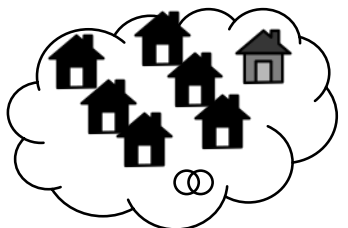

Downstream of a supply point

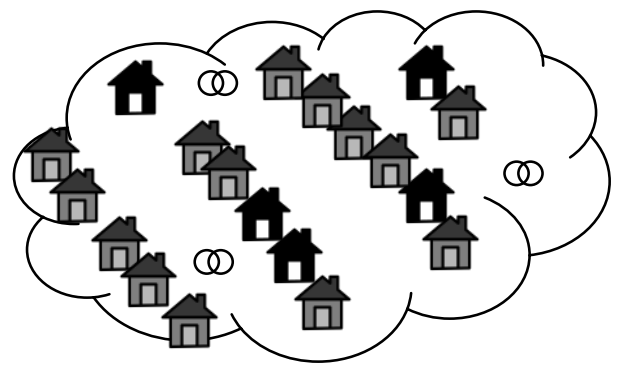

Distributed around the Network

Q LV transformer
Fig. 1 Community energy scheme layouts

\section{A. Community Projects}

Community energy project numbers have increased in recent years due to an increased element of research funding. In the UK this is largely through Technology strategy Board (TSB) Innovate UK projects, Low Carbon Network (LCNF) and Department of Energy and Climate change (DECC) funding. In the EU there exists Horizon Framework grants. Community energy schemes currently in different stages of development in the UK include but are not limited to field trials and/or reported developments from small startup companies through to bigger well established players in the energy field. Examples include; Community Energy Services Company [7], Exergy Devices [8], Upside Energy [9], CENEX [10], Moixa [11], Tempus Energy [12], Kudos Energy [13] and OpenUtility [14]. Some of the technical solutions currently being reported are more geared to small industry rather than community energy at domestic properties for example Kiwi Power [15], Open Energi [16] and Cisco [17].

Examples of more Utility driven projects which include field trials include; Scottish and southern Energy projects; My electric avenue [18] looking at EV charging; Thames Valley Vision [19] looking to understand consumption and anticipate and support changes to Network management and SAVE [20] looking at DSM. Others include Western Power Distribution projects; FALCON [21] and project SYNC [22] which focus on industrial and commercial scale demand. UKPN projects include Low carbon London [23] which also focused on industrial and commercial customers, Smarter Network Storage [24] which includes energy storage and Vulnerable customers and energy efficiency [25] looking at DSM. These projects are very focused on Network issues and would require third party companies to deal with the commercial side.

Through EU funding there has been a number of larger and more involved projects with multiple consortia. A number of such projects in recent years typically include some form of VPP. Some examples of projects in this area include:

Ecogrid [26] is a large-scale field test on the Danish island of Bornholm (with follow on EU funding) to investigate how varying real-time price signals can influence the demand of electricity customers under fully automated, semi-automated and manual control. The trial included 1,900 electricity customers and up to 100 industry/commercial buildings with electric heating and heat pumps being the key managed loads. Solarserve [27] which is a VPP based project with generation and storage. The Combined Power Plant consists of three wind parks (12,6 MW), 20 solar power plants (5,5 MW), four biogas systems (4,0 MW) and the pump storage Goldisthal (Output: $1.060 \mathrm{MW}$; Storage: 80 hours, i.e. $8480 \mathrm{MWh}$ ). Project FENIX [28] which is another VPP based project with generation in the form of large scale and small domestic CHP. Project ADDRESS [29] included demand side management (mostly washing machines and water and electric heaters) of 263 consumers in Spain. Project PowerMatching City [30] looked at control of a number of households with a combination of PV, EV, hybrid heat pump, micro CHP plus energy storage.

There are also a significant number of schemes that are not directly community based but focus around an individual entity such as a single house looking into management of one or more combinations of load, PV, energy storage, heating or hot water, with the potential for scale up to community level. Examples include, but not limited to, passivsystems[31], British Gas[32], Geo Systems[33], Simtricity [34], PowerVault [35], Honeywell [36], Sneider [37], Eltako [38], Apple [39] and Wink [40].

\section{B. Components in Community Energy}

A community energy scheme with electrical energy control needs to be focused on controlling generation, storage and load at a number of residential properties. To this end, Fig. 2 shows 
an image of a house with a summary of those components which could be deemed controllable in some manner under a DSM scheme. There is also scope to consider common community loads such as street lights within a scheme.

The appliances may be controlled through plug sockets or by direct control through communication with the appliance. Control may be complicated by the operational constraints of the appliance and/or customer requirements [41]. In addition devices may be classified as shiftable and/or throttleable resulting in implicit constraints [42]. Examples of these are shown in Table II. Other electrical appliances such as lighting, TV and computers are typically defined as critical and turned on when required and so are unavailable for management.

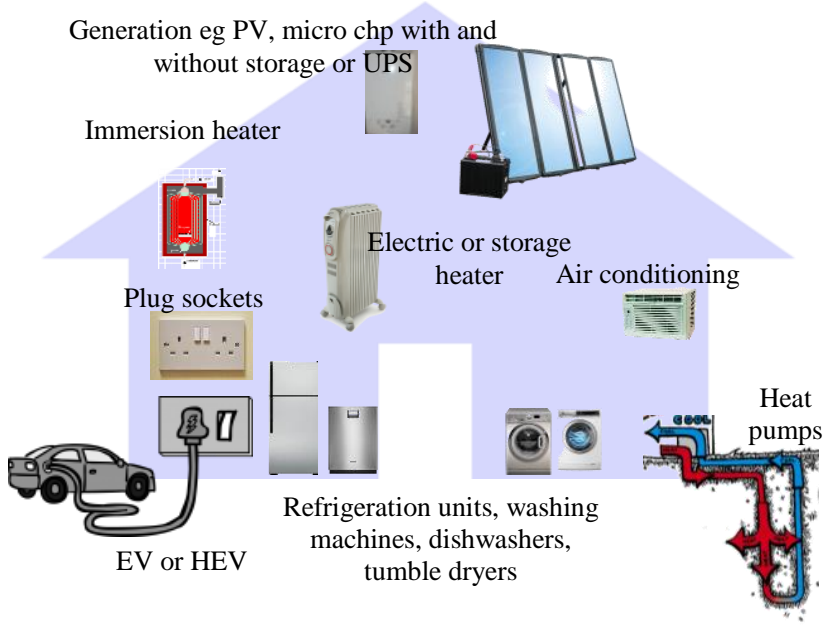

Fig. 2 Controllable DSM elements at a house

TABLE II.

DSM CONSTRAINT

\begin{tabular}{|l|l|l|}
\hline Device & $\begin{array}{l}\text { Constraint Time } \\
\text { period }\end{array}$ & Constraint \\
\hline Heat pump & Up to 10 minutes & Minimum operating time [18] \\
\hline $\begin{array}{l}\text { Appliances on } \\
\text { cyinterruptible }\end{array}$ & $\begin{array}{l}\text { Cycle time } \\
\text { around an hour }\end{array}$ & $\begin{array}{l}\text { Cycle completion to avoid issues such } \\
\text { as damp clothing sitting in a washing } \\
\text { machine. Typically shiftable with } \\
\text { fixed energy. }\end{array}$ \\
\hline $\begin{array}{l}\text { Appliances on } \\
\text { at all time }\end{array}$ & $\begin{array}{l}\text { Cooling/heating } \\
\text { cycle of device, } \\
(12-24 \text { minutes } \\
[42])\end{array}$ & $\begin{array}{l}\text { For example refrigeration units } \\
\text { reaching temperature thresholds. } \\
\text { These devices may be throttable i.e. } \\
\text { can operate at reduced power. }\end{array}$ \\
\hline $\begin{array}{l}\text { Heaters/ air } \\
\text { conditioning }\end{array}$ & $\begin{array}{l}\text { Cooling/heating } \\
\text { cycle of house }\end{array}$ & $\begin{array}{l}\text { Customer comfort threshold may also } \\
\text { be a function of external temperature } \\
\text { and insulation }\end{array}$ \\
\hline PV & daily & $\begin{array}{l}\text { Uncontrolled and subject to weather } \\
\text { settling time after full charge }\end{array}$ \\
\hline Energy storage & 10 minutes & \multicolumn{2}{|c|}{} \\
\hline
\end{tabular}

If it assumed that the generation sources (PV, wind) are uncontrollable, a community energy scheme typically has to have the following control over the appliances within a property subject to their constraints;

- Shifting the start time and hence load profile

- $\quad$ Reducing the input power (if possible)

- Importing/exporting power to energy storage devices

- Micro CHP electricity export
This local control (switching on and off devices) is typically reported as being achieved through the use of a local house controller as shown in Fig 3.

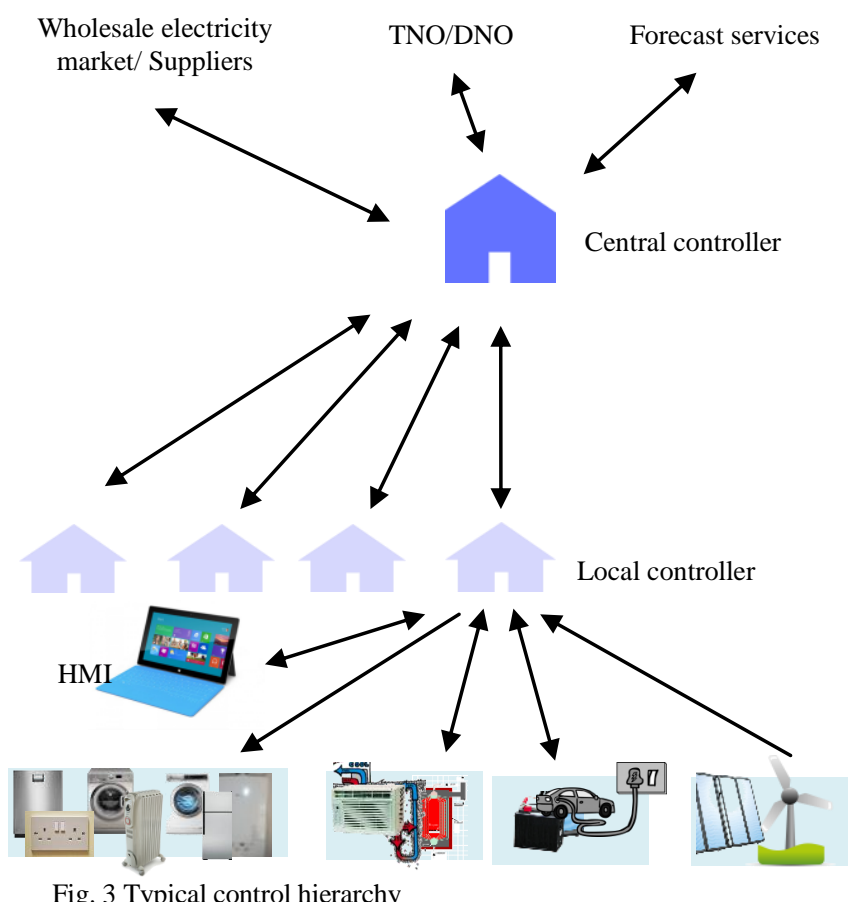

The role of this controller may include any combination of the following functionality;

- User interface and intervention. This may be through a number of media However, WiFi based lap tops, tablets and smart phones are looking to be the popular choice. All information from tariff, through to sensor data, to appliance state, to metering could be made accessible.

- Control of devices. This may be manual through the user interface, fully automatic including fixed and flexible scheduling or any combination in between.

- Sensors that can record and monitor any combination of; load demand, generation, battery monitoring, temperatures such as hot water, room temperature, freezer temperature, weather conditions that may affect generation such as solar radiation and wind speed measurements.

- Metering,

- Feedback to a central controller.

To co-ordinate properties for a community scheme, an overall controller is needed to look at information from all sources. Information fed back to this could include any combination of the data above and also include probabilistic loading, weather forecast based generation patterns. The difference between a community scheme and just an individual domestic property energy system is that large scale oversight and control is required to ensure that the community as a whole delivers on promises which may include helping with TNO or DNO services. The central controller requires to communicate with local controllers (possibly through Radio/3G/4G/Internet) Roles of a central control from Fig 3 could include; 
- Coordination with the energy market including obtaining and analyzing pricing and incentive info e.g. day ahead markets, time of use prices, one way price signal [18], giving customers access to multiple suppliers or different markets e.g. Enhanced Frequency Response (EFR) or Load Upturn services for the TNO.

- Analyzing information from the local controller e.g. customer data and other information such as weather forecast and generation patterns to look at prediction.

- Undertaking the calculations required to determine the load/energy storage switching patterns/schedules required and reporting this down to the local house controller.

- Delivering metering functionality (this may be over different time slots, $1 / 2$ hour, five minutes, every second) plus detailing and reporting customer benefits (fixed tariff, reduced costs).

The ability of the central controller is limited by the amount of load that can be controlled, the generation and any energy storage. Energy storage is in itself expensive to purchase and therefore the customer requires clear financial reward for installing this and allowing it to be operated. There exists a tradeoff therefore between the cost of purchasing extra storage against the additional benefits that this brings and how well it can be managed to get maximum benefits.

\section{ENERGY STORAGE SIZING}

Within literature there are a number of methodologies used to size and place large scale battery energy storage systems around the grid. The majority of these studies are either concerned with wind farm generation for both grid and nongrid connected systems $[43,44]$, with micro grids $[45,46]$ or with sizing and costing of systems for offsetting grid reinforcement costs $[47,48,49]$. The published work is split into theoretical studies and those with minimal real world validation typically on a microgrid. This work is further sub-divided into how life cycle and capacity fade are included within the sizing calculation. The capacity fade and life span can be ignore if the battery chemistry chosen has a low capacity fade and high life span not likely to be reached over the course of the life of the system.

For smaller properties such as those at domestic level, batteries were previously sized based on what is available in the market or sized to match a PV panel output. However, there is a growing interest in community energy and in particular the Virtual Energy District and Virtual power plants which include community schemes. There have been well over 1000 journal papers published in the last five years on how to size energy storage. These can be summarised as those that deal with remote island communities which may have no grid supply, for example those in references [50,51,52], and those which use complex optimisation techniques with and without both tariff and load information and with and without renewable generation. In some cases this ties around a building with a large load [53] whereas other schemes look at homes on an individual basis with and without solar generation $[54,55,56]$. What is clear is that the load and generation change with time and therefore the management of the energy storage and the algorithm behind this is key to obtain the maximum theoretical benefit that is available with hindsight using retrospectively fitted data. Different sizes which have turned up within literature include [55] 1000 homes with $5 \mathrm{~kW}$ battery (or $2 \mathrm{MW}$ per community) and [59] 1.3MW per community. Indications are within literature that there is diminishing return with larger batteries and that energy management control is key to getting the best response from the system.

\section{CONTROL SYSTEM}

The community energy system is looking to achieve a target (such as lowest customer electricity cost) through the optimisation of the controllable components in the community subject to technical and customer constraints. There may be more than one objective aim (e.g. reducing electricity export while aiming for lowest cost). In addition due to the changeable nature of the loads in the community the system must be flexible, adaptable and expandable to meet any number of properties. The communication between the central controller and the local controllers may therefore be limited in very large networks and may constrain the type of control and energy management available. For example, the simplest form of communication could be a one-way price signal to the local controller which the user has the chance to act upon.

\section{A. Energy Management Algorithm}

There are three main categories of energy management solution as shown in Table III.

TABLE III

MANAGEMENT TYPES

\begin{tabular}{|c|c|c|}
\hline Type A & Type B & Type C \\
\hline Management of & Separate & Basic provision of \\
multiple buildings, & management/control of & information with no \\
assets or appliances & individual appliances, \\
(aggregated) where & assets or buildings with no & control of buildings, \\
assets and buildings & connection between & assets or appliances \\
are connected and & multiple appliances or & and reliance on user \\
affect the & buildings / no overall & behaviour to take \\
management of one & management system & contion / manual \\
another & & \\
& & \\
& & \\
& &
\end{tabular}

Reference [14] undertook a project with 654 semiautomated households, 444 fully automated households, 500 manually controlled and a 350 reference group with load primarily based around electric heating. They determined that there was very little benefit from manual control type $C$. There are a significant number of control schemes described in literature around Type A and Type B control with any combination of generation, DSM and storage. Due to the control complexity involved in the former and the possible need for day ahead pricing strategies, it is most common to find control solutions based on Artificial Intelligence techniques. The most common of these is using multi-agent systems (MAS), where typically each property is an agent [60][61]. For systems which aim to optimise cost this may take the form of an auction between agents. Game theory has been more recently used as extensions of optimal control problems. An optimal control problem treats the situation where there is a single player with one objective function, whereas a game theory deals with the situation where multiple players interact with each other for their own purpose. These types of energy 
management strategy published in literature can be loosely split according to methodology as shown in Fig 4. There are many references available in each area associated with the methodologies - only a few example ones are given.

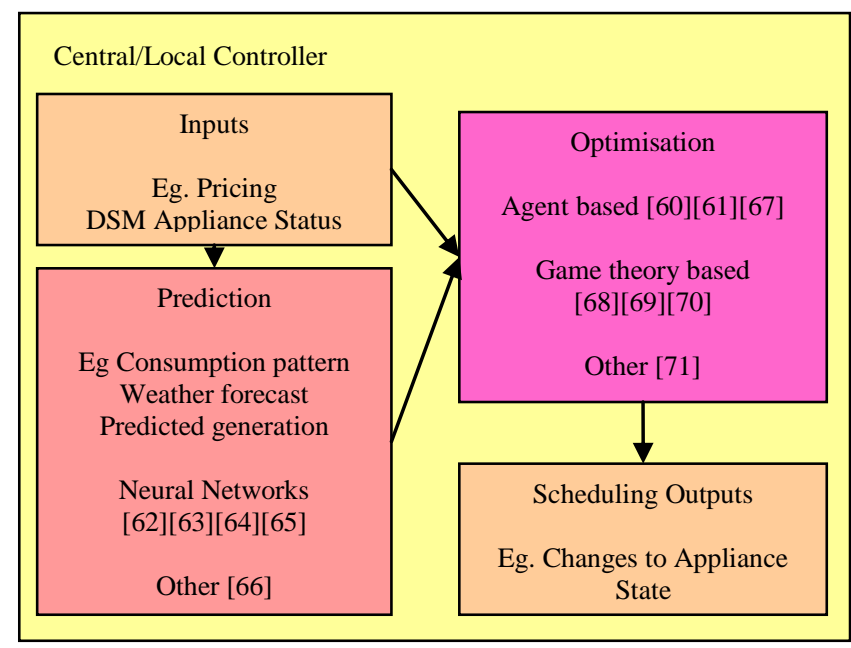

Fig. 4 Different Energy management strategies

\section{CONCLUSIONS}

There has been an increase in community energy projects over the last 10 years developed on the ability to control electrical and/or heat through the use of demand side, generation and energy storage management. However, there is still some way to go before these types of schemes can be made commercial.

TSB funded Project ORCSEN looked in detail at a prototype community-level demand control algorithm based on controlling DSM, generation and energy storage on all properties downstream of a local UK $11 \mathrm{kV}$ substation, both with and without perceived connection constraints, using the types of system described in this review paper and identified that:

- On a target network analysed, smart controls across multiple buildings coupled with appropriately deployed local generation and battery storage can reduce maximum load on substations by around $35 \%$ in winter and reduce minimum load (export) from $-36 \%$ to $-6 \%$ in summer.

- This level of load reduction could feed through to reduced network reinforcement costs if appropriate and hence support a business case for investment.

- In addition, this kind of technical solution has the potential to save end customers up to $9 \%$ on electricity bills via demand shifting and tariff optimisation (in addition to any direct benefits of microgeneration in the forms of avoided electricity purchase and feed-in tariffs).

- These benefits will vary significantly depending on the load and network configuration below the sub-station, and in some cases the impact may be negligible. This means the value of smart grid control technologies and community management algorithms is likely to vary significantly across the network and makes overall potential market size difficult to validate.

- The calculated benefits are highly dependent on the effectiveness of the control and optimisation algorithm along with associated predictive techniques.

- Energy storage sizing may impact the business case as over sized storage could prove too expensive and undersized storage will not meet required aims especially within a constrained Network.

In principle there should also be benefits in providing greater resilience to large scale solar PV deployment due to the positive impact demonstrated in this study in reducing overall electricity exports in summer. The next stages in energy management should be thorough testing of control solutions to prove that it is safe to deploy on a constrained network and that business case assumptions are validated.

\section{REFERENCES}

[1] S. J. W. Klein and S. Coffey, "Building a sustainable energy future, one community at a time," Renew. Sustain. Energy Rev., vol. 60, pp. $867-$ 880, Jul. 2016.

[2] Ö. Yildiz, J. Rommel, S. Debor, L. Holstenkamp, F. Mey, J. R. Müller, J. Radtke, and J. Rognli, "Renewable energy cooperatives as gatekeepers or facilitators? Recent developments in Germany and a multidisciplinary research agenda," Energy Res. Soc. Sci., vol. 6, pp. 59-73, Mar. 2015.

[3] T. van der Schoor, H. van Lente, B. Scholtens, and A. Peine, "Challenging obduracy: How local communities transform the energy system,” Energy Res. Soc. Sci., vol. 13, pp. 94-105, Mar. 2016.

[4] B. P. Koirala, E. Koliou, J. Friege, R. A. Hakvoort, and P. M. Herder, "Energetic communities for community energy: A review of key issues and trends shaping integrated community energy systems," Renew. Sustain. Energy Rev., vol. 56, pp. 722-744, Apr. 2016.H.

[5] Saboori; M. Mohammadi; R. Taghe, "Virtual Power Plant (VPP), Definition, Concept, Components and Types", Power and Energy Engineering Conference (APPEEC), 2011 Asia-Pacific.

[6] D. Menniti; N. Sorrentino; A. Pinnarelli; A. Burgio; G. Brusco; G. Belli "In the future Smart Cities: Coordination of micro Smart Grids in a Virtual Energy District", Power Electronics, Electrical Drives, Automation and Motion (SPEEDAM), 2014 International Symposium.

[7] http://www.energylocal.co.uk/ accessed online April 2016

[8] http://exergydevices.co.uk/ accessed online April 2016

[9] http://upsideenergy.co.uk/ accessed online April 2016

[10] http://www.cenex.co.uk/case-studies/ebbs-flows-energy-systems-efesproject/ accessed online April 2016

[11] http://www.moixatechnology.com/ accessed online April 2016

[12] www.tempusenergy.com accessed online April 2016

[13] http://www.cepro.co.uk/ accessed online April 2016

[14] https://www.openutility.com/ accessed online April 2016

[15] http://www.kiwipowered.com/solutions/energy-intelligence-and-smartmetering accessed online April 2016

[16] http://www.openenergi.com/our-technology/ accessed online April 2016

[17] http://www.cisco.com/c/en/us/products/switches/energy-managementtechnology/index.html accessed online April 2016 accessed online April 2016

[18] http://myelectricavenue.info/our-trials accessed online April 2016

[19] http://www.thamesvalleyvision.co.uk/our-project/background/ accessed online April 2016

[20] https://www.ssepd.co.uk/save/ accessed online April 2016

[21] http://www.westernpowerinnovation.co.uk/Projects/Falcon.aspx accessed online April 2016

[22]http://www.westernpowerinnovation.co.uk/Projects/CurrentProjects/SYNC.aspx accessed online April 2016 
[23] http://innovation.ukpowernetworks.co.uk/innovation/en/Projects/tier-2projects/Low-Carbon-London-(LCL)/ accessed online April 2016

[24] http://innovation.ukpowernetworks.co.uk/innovation/en/Projects/tier-2projects/Smarter-Network-Storage-(SNS)/ accessed online April 2016

[25]http://innovation.ukpowernetworks.co.uk/innovation/en/researcharea/demand-side-response/\#SNS accessed online April 2016

[26]http://www.euecogrid.net/images/Documents/150917_EcoGrid\%20EU\%20Implement ation\%20to\%20Demonstration.pdf accessed online April 2016

[27] http://www.solarserver.com/solar-magazine/solar-energy-system-of-themonth/the-combined-power-plant.html accessed online April 2016 accessed online April 2016

[28] http://www.fenix-project.org/ accessed online April 2016

[29] http://www.addressfp7.org/index.html accessed online April 2016

[30] http://www.powermatchingcity.nl/site/pagina.php?id=46 accessed online April 2016

[31] https://www.passivsystems.com/ accessed online April 2016

[32] https://www.britishgas.co.uk/products-and-services/hive-activeheating.html accessed online April 2016

[33] http://www.geotogether.com/ accessed online April 2016

[34] http://www.cepro.co.uk/2013/05/simtricity/ accessed online April 2016

[35] http://www.powervault.co.uk/ accessed online April 2016

[36] http://yourhome.honeywell.com/ accessed online April 2016

[37] http://www.schneider-electric.com/ww/en/ accessed online April 2016

[38] http://www.eltako.com/en.html accessed online April 2016

[39] http://www.apple.com/uk/ios/homekit/ accessed online April 2016

[40] http://www.wink.com/about/ accessed online April 2016

[41] Baoshi Liu; Qi Wei, " Home energy control algorithm research based on demand response programs and user comfort", Measurement, Information and Control (ICMIC), 2013, Pages: 995 - 999

[42] J. D. Hobby, A. Shoshitaishvili, and G. H. Tucci, "Analysis and methodology to segregate residential electricity consumption in different taxonomies," IEEE Trans. Smart Grid, vol. 3, no. 1, pp. 217-224, Mar. 2012.

[43] Yasser Moustafa Atwa, E. F. El-Saadany, , "Optimal Allocation of ESS in Distribution Systems With a High Penetration of Wind Energy", IEEE Trans Power Systems, Vol. 25, No. 4, Nov 2010

[44] ZHANG Yingda, LIU Nian, ZHANG Jianhua "Optimum Sizing of Nongrid-connected Wind Power System Incorporating Battery-exchange Stations", 2012 IEEE 7th International Power Electronics and Motion Control Conference - ECCE Asia, June 2-5, 2012, Harbin, China

[45] D.P. Jenkins J. Fletcher D. Kane "Lifetime prediction and sizing of leadacid batteries for microgeneration storage applications",IET Renewable Power Generation, April 2008

[46] Ajai Gupta*, R P Saini, and M P Sharma, "Hybrid Energy System Sizing Incorporating Battery Storage: An Analysis via Simulation Calculation" 2009 Third International Conference on Power Systems, Kharagpur, INDIA December 27-29

[47] Rau, Taylor "A central inventory of storage and other technologies to defer distribution upgrades - optimisation and economics" IEEE Transactions on Power Delivery, Vol. 13, No. 1, January 1998

[48] T. Logenthiran, Dipti Srinivasan "Intelligent Management of Distributed Storage Elements in a Smart Grid" IEEE PEDS 2011, Singapore, 5 - 8 December 2011January 1998

[49] D Strickland, X Bai , "Sizing Energy Storage on the $11 \mathrm{kV}$ Distribution Network", PEMD 2014

[50] http://www.meetmaslow.com/technical-specification/

[51] http://www.teslamotors.com/en_GB/powerwall

[52]http://www.westernpowerinnovation.co.uk/Documentlibrary/2015/Project-FALCON-Engineering-Trials-Batteries.aspx

[53] Chad Abbey; GÉza Joos , "A Stochastic Optimization Approach to Rating of Energy Storage Systems in Wind-Diesel Isolated Grids" , IEEE Transactions on Power Systems, Year: 2009, Volume: 24, Issue: 1 Pages: $418-426$
[54] Michael Ross; Chad Abbey; Géza Joós, "Cost analysis for sizing energy storage systems in wind-diesel microgrids", Power and Energy Society General Meeting, 2011 IEEE Year: 2011,Pages: 1 - 8

[55] Michael Ross; Rodrigo Hidalgo; Chad Abbey; Géza Joós, "Analysis of Energy Storage sizing and technologies", Electric Power and Energy Conference (EPEC), 2010 IEEE, Year: 2010 Pages: 1 - 6

[56] Lokesh Kumar Panwar; K Srikanth Reddy; Rajesh Kumar , "Ecoeconomie sizing of autonomous hybrid energy system (AHES) using particle swarm optimization (PSO)".Advances in Green Energy (ICAGE), 2014 International Conference on. Year: 2014,Pp: 233 - 238

[57] Stefano Squartini; Matteo Boaro; Francesco De Angelis; Danilo Fuselli; Francesco Piazza, "Optimization algorithms for home energy resource scheduling in presence of data uncertainty", Intelligent Control and Information Processing (ICICIP), 2013 Pages: 323 - 328

[58] Tetsuzo Yoshimura; Ryo Kanamori; Takao Ito,"Evaluation of Community-Based Electric Power Market with Multi-agent Simulation”, Service-Oriented Computing and Applications (SOCA), 2013 IEEE 6th International Conference on, Year: 2013,Pages: 343 - 347, DOI:

[59] D. Menniti; A. Pinnarelli; N. Sorrentino; A. Burgio; G. Belli, "Management of storage systems in local electricity market to avoid renewable power curtailment in distribution network", Power Engineering Conference (AUPEC), 2014 Australasian Universities,

[60] Albert Molderink; Vincent Bakker; Maurice G. C. Bosman; Johann L. Hurink; Gerard J. M. Smit, "Management and Control of Domestic Smart Grid Technology", IEEE Transactions on Smart Grid, 2010, Volume: 1, Issue: 2

[61] Chen Wang; Tengfei Zhang; Fumin Ma "A multi-agent based hierarchical control system for DERs management in islanded microgrid", Chinese Automation Congress (CAC), 2015

[62] Irena Koprinska; Mashud Rana; Alicia Troncoso; Francisco MartínezÁlvarez, "Combining pattern sequence similarity with neural networks for forecasting electricity demand time series", Neural Networks IJCNN, 2013

[63] Wenyu Zhang; Yuanyuan Wang; Jianzhou Wang; Jinzhao Liang, "Electricity Demand Forecasting Based on Feedforward Neural Network Training by a Novel Hybrid Evolutionary Algorithm", Computer Engineering and Technology, 2009. ICCET '09. Pages: 98 - 102

[64] P. Mandal; T. Senjyu; K. Uezato; T. Funabashi, “ Forecasting severalhours-ahead electricity demand using neural network", Electric Utility Deregulation, Restructuring and Power Technologies, 2004, IEEE Vol: 2, Pages: $515-521$

[65] Filipe Azevedo; Zita A. Vale, "Forecasting Electricity Prices with Historical Statistical Information using Neural Networks and Clustering Techniques",2006 IEEE PES Power Systems Conference and Exposition

[66] D. B. L. Bong; J. Y. B. Tan; K. C. Lai, "Application of multilayer perceptron with backpropagation algorithm and regression analysis for long-term forecast of electricity demand: A comparison”, Electronic Design, 2008. Pp: $1-5$

[67 ]M. P. F. Hommelberg; C. J. Warmer; I. G. Kamphuis; J. K. Kok; G. J. Schaeffer, "Distributed Control Concepts using Multi-Agent technology and Automatic Markets: An indispensable feature of smart power grids", Power Engineering Society General Meeting, 2007.

[68] Ryohei Arai; Koji Yamamoto; Takayuki Nishio; Masahiro Morikura, "Impact of communication availability in a demand-side energy management system: Differential game-theoretic approach" 2013 IEEE Globecom Workshops (GC Wkshps)

[69] Hazem M. Soliman and Alberto Leon-Garcia "Game-Theoretic DemandSide Management With Storage Devices for the Future Smart Grid", IEEE Trans smart grid May 2014, availabe at http://de.mathworks.com/matlabcentral/answers/uploaded_files/16876/1 0.1109@TSG.2014.2302245.pdf

[70] Nguyen, P. H.; Kling, W. L.; Ribeiro, P. F. "A Game Theory Strategy to Integrate Distributed Agent-Based Functions in Smart Grids", Smart Grid, IEEE Transactions on, On page(s): 568 - 576 Volume: 4, Issue: 1, March 2013

[71] R. Caldon; A. R. Patria; R. Turri, "Optimisation algorithm for a virtual power plant operation",Universities Power Engineering Conference, 2004. UPEC 2004. 39th International,Pages: 1058 - 1062 vol. 2 